\title{
Discursos y estrategias en torno a la conciliación de la vida laboral y familiar en la negociación colectiva
}

\author{
Pilar Carrasquer \\ Matilde Massó \\ Antonio Martín Artiles
}

Universitat Autònoma de Barcelona. Departament de Sociologia

Grup d'Estudis Sociològics sobre la Vida Quotidiana i el Treball

08193 Bellaterra (Barcelona). Spain

Pilar.carrasquer@uab.cat

Matilde.masso@uab.cat

Antonio.martín@uab.cat

\section{Resumen}

Este artículo tiene como objetivo examinar cinco hipótesis relacionadas con el desarrollo de la Ley de Conciliación de la Vida Laboral y Familiar, su implantación a través de la negociación colectiva y el significado que adopta el concepto de conciliación para los distintos actores sociales. Los resultados de nuestra investigación muestran que, si bien las políticas europeas de empleo han desempeñado un "papel inductor» de dicha temática, ésta ocupa un lugar secundario en la negociación colectiva. A su vez, mientras que los sindicatos entienden la conciliación como un tema a gestionar a través del diálogo social, los empresarios la derivan al ámbito de la gestión de recursos humanos.

Palabras clave: gobernanza, subsidiariedad, negociación colectiva, conciliación, igualdad de oportunidades, buenas prácticas.

\section{Abstract. Discourses and strategies on work life balance in the collective bargaining}

This article examines five hypotheses related to the development and implementation of the Work Life Balance Law through collective bargaining, and to the meaning that the notion of work life balance acquires to the different social actors. The results of the research suggest that while the European employment policy plays an «inferred effect» of this issue, it keeps a secondary place in the collective bargaining. Also while trade unions understand the notion of work life balance as a question to be managed through collective bargaining, employers place it in the domain of the individualized management characteristic of the human resources policy.

Key words: governance, collective bargaining, gobernability, work life balance, equal opportunities, best practices. 


\section{Sumario}

\section{Introducción 4. Algunos resultados}

2. La importancia del marco comunitario europeo en el desarrollo de las políticas de conciliación en España

3. Hipótesis generales y estrategia de 5. Conclusiones

Entrevistas referenciadas

Bibliografía investigación

\section{Introducción}

En este artículo presentamos los resultados de nuestro análisis del desarrollo de la ley española de conciliación y su implantación y difusión mediante la negociación colectiva. Un análisis realizado a través del concepto de gobernanza, y atendiendo al significado que los distintos actores sociales atribuyen a la conciliación ${ }^{1}$. A diferencia de otras aproximaciones, nos ha interesado indagar en las potencialidades y en los posibles límites que la negociación colectiva presenta como procedimiento capaz de introducir y gestionar la conciliación en el ámbito laboral. Todo ello al hilo de las hipótesis que han orientado nuestro trabajo, cuyos resultados han refrendado, en parte, la bondad de las mismas y de una estrategia de investigación basada en el análisis tipológico y en el estudio de casos.

Así, en primer lugar, hemos podido corroborar la idea de que las directivas europeas han desempeñado un importante papel inductor en la inclusión de la conciliación en la agenda de la negociación colectiva; una cuestión que, de otro modo, probablemente no estaría hoy presente con el mismo nivel de significación. En segundo lugar, mostramos que, a pesar de la inclusión de esta temática en la agenda de negociación, la conciliación sólo tiene un papel secundario en el diálogo social. A este respecto, partíamos de considerar que la capacidad de difusión e irradiación de la conciliación en la agenda de negociación dependía de la estructura de la negociación colectiva. Por un lado, una estructura centralizada de la negociación colectiva permitiría una mejor coordinación, articulación, irradiación y administración de los objetivos propuestos y los acuerdos alcanzados. Mientras que, por otro lado, una estructura descentralizada de la negociación colectiva obstaculizaría la difusión y la irradiación de

1. El presente artículo se enmarca en la investigación DGYCIT (contrato SEC 2001-2543), que lleva como título El tiempo de trabajo en la negociación colectiva y sus efectos sociales, desarrollada por el grupo QUIT-Departamento de Sociología de la UAB. En dicha investigación, nos habíamos propuesto abordar la temática del tiempo de trabajo desde una perspectiva plural que abarcase distintas problemáticas de actualidad y que, al mismo tiempo, permitiese el desarrollo de enfoques metodológicos diversos. Una de las problemáticas centrales de esta investigación ha sido justamente la que nos ocupa en estas páginas: el análisis de la conciliación de la vida familiar y laboral desde el punto de vista del discurso y la estrategia de los actores para impulsar la conciliación a través de la negociación colectiva. Otros artículos de este mismo número dan cuenta de esas distintas problemáticas abordadas. 
los objetivos, de modo que los resultados en las mesas de negociación serían más dispersos.

El significado de la conciliación sería, a su vez, susceptible de diversas interpretaciones para los actores involucrados en la negociación. Tal como hemos podido comprobar, la dirección de recursos humanos tiende a gestionar de forma individualizada los temas relacionados con la conciliación entre la vida laboral y familiar, mientras que los sindicatos tratan de impulsar esta temática desde la acción colectiva y bajo un planteamiento distinto: la conciliación abarcaría también la vida personal, y no exclusivamente la familiar.

Finalmente, hemos analizado el significado y la utilización discursiva de las llamadas buenas prácticas. Como mostraremos posteriormente, éstas constituyen sólo una cierta mejora de lo dispuesto por la ley, pero se trata, además, de prácticas limitadas y exclusivas a ciertos segmentos del empleo o bien de prácticas destinadas a la mejora de la legitimidad pública de las propias empresas.

\section{La importancia del marco comunitario europeo en el desarrollo de las políticas de conciliación en España}

La problemática que se plantea hoy bajo el concepto de conciliación no es nueva, aunque, por lo general, ha tenido escasa relevancia en las estrategias de los actores sociales en el ámbito laboral y en los contenidos de sus propuestas de intervención y de negociación ${ }^{2}$. En este sentido, nos preguntábamos: ¿por qué ha venido adquiriendo una mayor presencia el tema de la conciliación en las relaciones laborales? A nuestro modo de ver, esta cuestión está estrechamente relacionada con la política laboral de la Unión Europea y con la idea de gobernanza entendida como proceso de decisión política articulada en diferentes niveles. La premisa que orienta la conciliación, como línea de acción política en el plano de la Unión Europea, está vinculada a los objetivos de mantenimiento del modelo social europeo ${ }^{3}$. Las previsiones sobre el futuro del modelo social y del mercado laboral de la Unión Europea, realizadas a principios de la década de los noventa en el llamado Libro Blanco, constituyen un documento de referencia fundamental, donde se plantean los grandes retos de futuro y la orientación de la política laboral y social de la Unión. En ese documento de orientación política y estratégica, se esbozan las líneas básicas que se irán desarrollando desde la década de los noventa.

2. Ésta es una cuestión que se desarrolla en otro artículo de este número (Torns y otros), a cuya bibliografía nos remitimos.

3. El modelo social europeo se entiende como un modelo alternativo al capitalismo de mercado, orientado al corto plazo. El Libro Blanco de Delors se inscribe en esta posición política alternativa al capitalismo puramente neoliberal y de mercado (véase Michel Albert, 1992 y 1996). Esta posición es hoy también sostenida por el Congreso de la Confederación Europea de Sindicatos (ETUI, 2003), donde se argumenta la necesidad de inscribir la idea de «economía social de mercado» en la futura Constitución de la UE. 
Tal como se afirma desde la Unión Europea, el Tratado de Ámsterdam institucionaliza el procedimiento aprobado en Essen: refuerza la coordinación de las políticas nacionales de empleo y prevé la definición de orientaciones comunes que podrían conducir a la adopción de recomendaciones a los estados miembro ${ }^{4}$. Así pues, el Tratado de Ámsterdam de 1997 y su posterior desarrollo en la cumbre extraordinaria de Luxemburgo, marcan la estrategia comunitaria sobre el empleo. Y todo ello en un doble plano: en el plano de los contenidos (objetivos en materia de políticas de empleo) y en el plano de la forma de implementar, gobernar, si se prefiere, dicha estrategia comunitaria.

En ese momento, 1997, aparece por primera vez la necesidad de promover la conciliación entre vida laboral y familiar, dentro del pilar IV dedicado a reforzar la igualdad de oportunidades entre hombres y mujeres. Así, desde la perspectiva europea, la conciliación aparece ligada a la consecución de los objetivos de empleo comunitarios, pero situada en el marco concreto de la estrategia comunitaria de atajar las desigualdades y discriminaciones por razón de género en el empleo, así como para elevar las tasas de actividad femenina. A nuestro parecer, esta ubicación va a marcar las orientaciones y el desarrollo en materia de conciliación, cuando menos en el caso español.

A través del concepto de gobernanza, hemos querido abordar la complejidad de los procesos de decisión en la Unión Europea y hemos podido comprobar como, a veces, la iniciativa política se anticipa a la realidad de las relaciones laborales. En el caso de la conciliación de la vida laboral y familiar, las directrices europeas recogen una serie de contenidos innovadores que no reflejan las prácticas concretas impulsadas por la negociación colectiva de la mayoría de los países miembros, tal como sucede en el caso de España. Este hecho constituye una singularidad política relevante que en la teoría política se conoce con el nombre de "efecto inducido" 5 .

El objetivo político que persiguen la Unión Europea y los actores sociales es la defensa y el mantenimiento del modelo social europeo a través de la plena movilización de la mano de obra disponible, en particular de la mano de obra femenina, con objeto de garantizar el mantenimiento de los sistemas de protección social y, en términos generales, con vistas a garantizar el modelo social europeo. Con mayor empeño, si cabe, en un contexto de cambios sociodemográficos en el que el envejecimiento de la población exige un esfuerzo, tanto en el plano del diseño de estrategias para mantener los actuales sistemas de protección social, como en el plano de la puesta en marcha de servicios que

4. Véase, sobre este particular, el documento de la Comisión Europea (2003) [documento consolidado http://www.europa.eu.int/scadplus/leg/es/cha/c10228.htm].

5. La teoría del «efecto inducido», de origen funcionalista, se refiere al efecto de convergencia institucional que se deriva de la estructura económica y jurídica: la industrialización impone una pauta común a todas las sociedades modernas. En este caso, el concepto pone de relieve la importancia que tiene el acervo jurídico comunitario, las directivas europeas y la influencia de la jurisprudencia del Tribunal de Justicia Europeo en el proceso de convergencia (Scharpf, 2000). 
mejoren el cuidado y la atención cotidiana de las personas. En este sentido, la movilización de la mano de obra femenina podría responder a un doble objetivo. Por un lado, el de lograr esos niveles de empleo deseados, al tiempo que se garantiza el avance en lo que se refiere a la presencia paritaria de hombres y mujeres en el empleo. Pero, por otro lado, la mano de obra femenina también constituiría un contingente susceptible de ser empleado en los servicios emergentes. Algunos analistas van más allá, sugiriendo el ahorro de mano de obra inmigrada no comunitaria que ello significaría (Macinnes, 2004).

La intervención en materia de conciliación es susceptible de incentivar la presencia femenina en el empleo. El proceso mediante el cual se lleva a cabo su implementación en los distintos estados miembro pretendería influir en la toma de consideración de esta problemática, la conciliación, a la par que dejaría suficiente margen de actuación a los interlocutores sociales a nivel estatal para alcanzar los acuerdos que en cada realidad puedan suscribirse. Así pues, desde la Unión Europea, se marcan unos objetivos mínimos, un mínimo denominador común, pero no se coartan los máximos posibles a alcanzar en esta materia. Entendemos que éste es el caso de lo que sucede con el tema de la conciliación y por ello nos ha interesado analizar los contenidos que adopta la conciliación en el caso español y el contexto en el que se ubica esta cuestión.

En efecto, la decisión de impulsar una normativa europea sobre conciliación se ha tomado bajo el principio de subsidiariedad, que es un modo de promover la autorregulación entre los actores sociales (CES, UNICE, CEEP y sus equivalentes en los estados miembro). En este punto, resulta clave observar el posicionamiento de los actores sociales con respecto al tema que nos ocupa, pues de ello depende, en buena medida, el alcance y la orientación que la conciliación pueda tener. Por ello, la implementación de la normativa sobre la conciliación de la vida laboral y familiar y su posible mejora a través de todo este proceso, nos lleva también a considerar el concepto de gobernabilidad, referido al modo de control, seguimiento, aplicación y administración de la legislación y de los acuerdos.

\subsection{Gobernanza y subsidiariedad: el modo de hacer de la Unión Europea}

El concepto gobernanza alude a un nuevo modo de gobernar en diferentes niveles y de manera coordinada. La moderna gobernanza trata de significar una forma más cooperativa de gobernación que difiere de las viejas formas jerárquicas mediante las cuales las autoridades públicas han ejercido la soberanía y el control sobre los grupos de ciudadanos. En pocas palabras, la gobernanza alude a la idea de mediación entre las autoridades y la sociedad civil (Mayntz, 2002), el estado y las instituciones no estatales, públicas y privadas, así como los actores sociales que participan y cooperan en la formulación e implementación de las políticas públicas. La gobernanza implica una cierta delegación de funciones a los actores públicos y privados, tal como también ha sido observado en las definiciones teóricas del neocorporativismo (Schmitter, 
1988). En este sentido, la estructura de la moderna gobernanza no se caracteriza por su jerarquía, sino por la autonomía corporativa de los actores, así como por la creación de redes interorganizativas. La gobernanza es, a su vez, un modo de gobierno en el marco de la integración europea para abordar problemas que van más allá del estado nación, como son, a modo de ejemplo, los problemas económicos y los problemas ecológicos.

La gobernanza comporta que, a través de los actores sociales y de las instituciones, se concierta y se coordinan determinadas acciones sobre el mercado laboral. Esta vía exige notables esfuerzos de coordinación en diferentes niveles y se orienta por el principio de subsidiariedad. En este sentido, el mecanismo previsto en el acervo jurídico comunitario consiste en delegar la capacidad de regulación y de lograr un posible acuerdo de los actores sociales (CES, UNICE y CEEP) a través del diálogo social ${ }^{6}$. Posteriormente, si hay acuerdo, la Comisión Europea propone al Consejo la edición de una directiva que acabará siendo transpuesta a la legislación de los estados miembro ${ }^{7}$. Éste es el caso de las directivas sobre la conciliación de la vida laboral y familiar que hemos explorado.

Como escenario de fondo, el nuevo espacio político que genera la globalización y la integración europea es transnacional y exigiría abordar los problemas desde niveles más amplios y coordinar las medidas en distintos niveles jerárquicos. Esto es lo que ocurre en materia de coordinación de la política de empleo, establecida en el Tratado de Ámsterdam y que prevé la formulación de los Planes Nacionales de Acción por el Empleo (PNAE, en adelante), a partir de la consulta y negociación con los actores nacionales. Éstos presentan a la Comisión dicho PNAE, que lo remite al Consejo. Posteriormente, éste lo puede transformar en directivas y recomendaciones que, a su vez, los estados miembro deben implementar a través de la legislación laboral, tal como se prevé en el caso concreto de las directivas europeas en materia de conciliación. De este modo, a través de la coordinación de las políticas de empleo guiadas por los «cuatro pilares» e impulsadas a través de los PNAE, se han venido extendiendo determinadas medidas, tales como el trabajo a tiempo parcial, la flexibilización y reordenación del tiempo de trabajo o la propia temática específicamente ligada a la conciliación entre la vida laboral y la familiar. Uno de los instrumentos privilegiados para impulsar esta política es la negociación colectiva. De ahí nuestro propósito de examinar cómo se articulan los objetivos

6. Véase Köhler y Martín (2005: 582-583).

7. Esta forma de gobernanza es propia de los países de capitalismo avanzado, con estructuras institucionales y organizaciones sociales complejas. En este tipo de escenario, la interdependencia económica exigiría la necesidad de coordinación entre los actores colectivos, así como entre los individuos y las instituciones públicas y privadas, como señala Scharpf (2000). El mercado por sí sólo no parece ser capaz de resolver los problemas y las exigencias de coordinación. En el Libro Blanco de la Comisión sobre la "Gobernanza» Europea, ésta se define como las normas, los procesos y los comportamientos que influyen en el ejercicio de los poderes en el ámbito europeo. La gobernanza comporta la responsabilidad y la participación de la ciudadanía y de los actores sociales en los procesos de decisión, para que éstos sean coherentes y articulados en distintos niveles. 
generales perseguidos por las instituciones europeas a través de la negociación colectiva y su concreción en los centros de trabajo en nuestro país.

\subsection{El principio de subsidiariedad como forma de autorregulación: la coordinación multinivel a través de la negociación colectiva}

El principio de subsidiariedad subraya la idea de que los procesos de decisión se deben tomar lo más cerca posible de la ciudadanía. En este sentido, las autoridades públicas delegan a la autonomía colectiva de las partes (es decir, a los propios actores) la posibilidad de negociar y alcanzar acuerdos, mediante los cuales se construyen los primeros procesos de decisión política. Después, el Gobierno nacional asume dicho acuerdo y su posterior implementación mediante ley. Este mismo mecanismo está instalado en el modo de operar de la Unión Europea: la Unión traduce los acuerdos entre los actores sociales en una directiva comunitaria, que posteriormente se transpone a la legislación de los estados miembro. Mayntz (2001) entiende este principio de subsidiariedad como una forma de autorregulación social. Así, las «corporaciones privadas» desarrollan funciones que el interés público y el estado le han asignado, explícita o implícitamente.

En efecto, una de las formas de autorregulación es la negociación entre intereses opuestos (entre las corporaciones privadas) como paso previo a la posterior implementación del acuerdo alcanzado por parte del gobierno que impulsa su desarrollo legal. Este procedimiento se ha extendido durante la década de los noventa como forma de regulación de las relaciones laborales en los países de la UE, lo que algunos analistas califican como regulación suave (soft regulation). En el ámbito supranacional, este principio de subsidiaridad está recogido en el artículo 139 del Tratado de Maastricht. Sin embargo, la Confederación Europea de Sindicatos (Köhler y Martín, 2005) entiende que dicho principio de subsidiariedad es interpretado habitualmente de forma restrictiva, postulando la no-intervención en el mercado y dejando que los actores se pongan de acuerdo a través del diálogo social. No siempre hay voluntad y posibilidades para el diálogo y el acuerdo. En muchas materias, la posibilidad de negociación entre los actores es francamente limitada, razón por la cual muchas iniciativas de ámbito europeo se acaban congelando o diluyendo por falta de iniciativa legislativa.

Así mismo, por último, el principio de subsidiariedad en la Unión Europea sustenta sus procesos de decisión en el estudio de las denominadas buenas prácticas (best practices), que se definen como experiencias modélicas en determinados campos de la política que la Unión Europea pone como ejemplo a seguir, o que incluso pueden servir de base para elaborar futuras directivas o recomendaciones a los estados miembro. Por esta razón, también hemos explorado un caso de buenas prácticas con objeto de ilustrar sobre futuros perfiles y pautas políticas susceptibles de desarrollo en materia de conciliación.

Éste es, en síntesis, el conjunto de planteamientos que han servido de soporte para la formulación de las hipótesis que han guiado nuestra investigación 
en lo que concierne al aspecto que aquí nos ocupa, y que detallamos a continuación.

\section{Hipótesis generales y estrategia de investigación}

La directiva europea de conciliación es, en cierto modo, una propuesta avanzada y previsora que trata de corregir y evitar un escenario demográfico de futuro sombrío. En este caso, precisamente, la gobernanza sobre la conciliación trata de coordinar, articular y reorientar las políticas laborales y sociales en un escenario de gobierno de las relaciones laborales en diferentes niveles o, si se quiere, multinivel. Dicho de otro modo, el marco legal inducido por la UE constituye posiblemente una vía para ir introduciendo gradualmente ciertos derechos de ciudadanía social en las relaciones laborales de los centros de trabajo. Las directivas europeas han tenido un «efecto inducido", impulsor y difusor de la política de conciliación en la negociación colectiva española.

Sin embargo, estimamos hipotéticamente que la conciliación entre la vida laboral y familiar no ocupa un lugar central en la negociación colectiva. En cierto modo, es un tema secundario para los actores sociales en el centro de trabajo. Las prioridades de éstos lo constituyen otros temas clásicos, como es especialmente la cuestión salarial y la jornada laboral, y, en menor medida, la regulación de la inestabilidad laboral.

A priori, nos parecía que aquellas estructuras de negociación colectiva más centralizadas serían más coherentes entre los distintos niveles de negociación y, por tanto, más propicias para la introducción de cláusulas sobre la conciliación de la vida laboral y familiar, que aquellas estructuras descentralizadas y aparentemente más ingobernables. Las estructuras centralizadas tienden a orientar la conciliación de la vida laboral y familiar a partir de los parámetros de las políticas laborales y de los acuerdos alcanzados en los convenios colectivos. Esta orientación, más o menos armonizada, se ve favorecida por la articulación y coordinación de los distintos niveles de negociación. Sin embargo, posiblemente la capacidad para negociar e introducir las cláusulas sobre la conciliación entre la vida laboral y familiar radiquen más bien en uno de los aspectos de la gobernanza: en la capacidad de gobernabilidad de los actores sociales, en la presencia de grupos organizados en los centros de trabajo, en su capacidad para perseguir, desarrollar y controlar determinados objetivos, como es la conciliación (Traxler, 2002).

No obstante, la eficacia de la negociación colectiva para introducir una política de conciliación de la vida laboral y familiar parece limitada, por cuanto, en la práctica, esta negociación afecta de manera desigual según las categorías jerárquicas y los niveles de cualificación. Las cualificaciones altas, así como los altos niveles jerárquicos, podrían constituir los colectivos que más se estén beneficiando de las políticas de conciliación entre la vida laboral y familiar. Estos colectivos podrían estar amparados por acuerdos relacionados con el flexi-time, es decir, cierta autonomía para adoptar horarios flexibles en la jornada laboral, al menos en lo que se refiere a las horas de entrada y salida, así como a la posi- 
bilidad de disponer de ciertos servicios o prestaciones para acomodar la demanda de tareas reproductivas (cuidado de hijos, guarderías, cuidado de ancianos, etc.). Posiblemente, una diferencia fundamental de este colectivo con relación al resto es que su posible capacidad de decisión para el uso flexible del tiempo de trabajo remunerado, clave desde el punto de vista de la conciliación, es de tipo individual y no se realiza a través de un acuerdo colectivo. Es por ello que algunos de los contenidos más relevantes sobre conciliación están inscritos en acuerdos individuales, a veces informales, basados en relaciones de confianza entre la dirección de recursos humanos y ciertas categorías profesionales altas. Por ello, sospechamos que esta política de gestión de recursos humanos se asimila más a prácticas empresariales para fidelizar y cooptar al personal cualificado que propiamente a una política de conciliación de la vida laboral y familiar. En especial, pero no exclusivamente, en lo que respecta a la gestión de la jornada laboral: en este sentido, quizá sea más sugerente hablar de una política de disponibilidad horaria para el personal cualificado.

En cambio, para las categorías profesionales y las cualificaciones más bajas, la capacidad de decisión estaría más bien sujeta a procesos colectivos y registrados en el convenio colectivo o en acuerdos de empresa o centro de trabajo. Para este colectivo, los contenidos de las medidas de conciliación ligadas a la gestión del tiempo son más limitadas y se refieren, en todo caso, a cláusulas relativas a la jornada laboral continua o a la posibilidad de combinar el trabajo a turnos, y están sujetas a otros requisitos empresariales, como la reorganización del tiempo de trabajo en función de la actividad productiva, a parte de los permisos regulados en convenio colectivo o en acuerdos de empresa que pueden constituir otro de los aspectos considerados ligados a la conciliación. En este sentido, nuestra hipótesis es crítica en relación con la extendida idealización de las políticas de conciliación que ha impulsado cierta literatura empresarial, como es el caso, por ejemplo, de Chinchilla y León (2003).

En relación con este particular, y finalmente, las buenas prácticas sobre conciliación no se deberían entender de una manera absoluta, sino en el sentido relativo a la situación actual de las cláusulas de conciliación que figuran en los convenios colectivos o en algunas prácticas de empresas. Algunos analistas (véase Bonino, Aragón, 2003: 17-19) entienden por buenas prácticas, aquellas «buenas cláusulas», "cláusulas de interés» o bien aquellos «ejemplos positivos» que pueden servir de referencia para otros convenios colectivos. Dicho de otro modo, la noción de buenas prácticas trata de identificar lo mejor que se ha hecho en materia de negociación de la conciliación. De ahí que el examen de las buenas prácticas nos puede aportar un abanico de cláusulas interesantes e imaginativas, pero también exige ciertas cautelas y reservas, en cuanto que el significado de las mismas quizá sólo sea explicable en el contexto de la empresa, del centro de trabajo y del tipo de actividad que se desarrolla.

Bajo estas premisas, nos ha parecido adecuado optar por una aproximación que nos permitiese indagar y analizar el discurso de los actores sociales, teniendo en cuenta el marco estructural de la negociación colectiva, con objeto de conocer cómo dichos actores afrontan la negociación y la regulación de la con- 
ciliación de la vida laboral y familiar, en sus diferentes niveles de negociación. Nos interesaba captar la dinámica del proceso, las estrategias y los objetivos de cada uno de los actores. Desde este punto de vista, se trata de una aproximación que aborda el problema de la conciliación desde una perspectiva dinámica y diferente a las interesantes contribuciones de los estudios jurídicos, tales como la de López y Valiño (2004) o la de Quintanilla (2005). El trabajo de campo se ha concretado en dos sectores de actividad (química y comercio-alimentación) que, a nuestro juicio, responden mejor a los dos tipos básicos de procesos y de situaciones que se pueden definir en torno a la gobernanza de la conciliación, según se trate de una estructura centralizada o descentralizada de negociación. Con objeto de abarcar el conjunto de niveles de negociación, con sus respectivos protagonistas, hemos realizado, además, un estudio de caso de dos empresas ilustrativas de cada uno de los sectores señalados. Esta tarea se ha completado con un balance sobre lo acordado en materia de conciliación; por este motivo, hemos examinado las cláusulas relacionadas con la cuestión, así como identificado un elenco de lo que se ha definido como buenas prácticas. En este sentido, por último, para el caso particular de análisis de las buenas prácticas, hemos seleccionado una empresa multinacional farmacéutica, caracterizada por su posición elevada en el ranking «Best place to work».

\section{Algunos resultados}

La estructura de la negociación colectiva influye en la gobernanza de la conciliación, pero también en el posicionamiento y en el significado que ésta tiene para los actores. Todo ello influye, a su vez, en el alcance de los acuerdos, en su contenido y en los colectivos que abarca. Su difusión y el cumplimiento de los acuerdos se diluye a medida que nos acercamos al centro de trabajo, salvo en aquellas ocasiones en que la propia conciliación pasa de ser un objeto de negociación a ser una herramienta de gestión empresarial. Así se podrían sintetizar los resultados más relevantes fruto de la exploración del proceso de gobernanza de la conciliación, a partir de las tres dimensiones que constituyen el entramado básico de nuestro trabajo (la estructura de la negociación colectiva, los distintos actores implicados y los posibles beneficiarios de la misma). A continuación argumentamos estos resultados, tomando como hilo conductor las principales hipótesis formuladas.

\subsection{La función impulsora de las directivas europeas y su transposición a la legislación española}

La transposición a la legislación española de las dos directivas europeas básicas sobre conciliación (la 92/85/CEE y la 96/34/CEE) ha desempeñado un papel inductor en las relaciones laborales. El desarrollo de los temas de conciliación entre la vida laboral y familiar en la negociación colectiva ha tenido efectos positivos, aunque también contradictorios. Los representantes sindicales que hemos entrevistado consideran que las directivas europeas y la ley 
española de conciliación de 1999, han tenido un papel revulsivo y difusor en el tema de la conciliación: ha facilitado la inclusión del tema en la agenda de negociación. Este hecho es formalmente importante en términos de difusión y sensibilización de los actores ante el problema de la conciliación. Como nos indican algunas de las personas entrevistadas: «La redundancia del articulado de la ley en los convenios colectivos es una estrategia para la difusión y consolidación de la propia ley. El cumplimiento de la ley no es automático» (E3) ${ }^{8}$. Este proceso de difusión de los objetivos de la ley y su articulación hacia los niveles inferiores de negociación (sector, empresa y centro de trabajo) es fundamental para la gobernanza multinivel. En términos de la gobernanza, una representante del comité de empresa europeo entrevistada subraya la importancia que han tenido la directiva y la ley a efectos de establecer políticas comparativas entre los distintos centros europeos, tales como encuestas sobre los códigos de conducta de la multinacional y las políticas de igualdad: «la comparación con otros centros del mismo grupo multinacional permite presionar aquí y criticar indirectamente la gestión paternalista. Eso influye en la posición de la dirección de recursos humanos de aquí» (E14). La actuación de los comités de empresas europeos abre una oportunidad para establecer elementos comparativos y a la vez presionar sobre la dirección de recursos humanos de los centros que no cumplan con la media general del grupo.

Asimismo, la ley ha tenido diferentes consecuencias en la práctica de los actores sociales. Elocuencia de ello son las siguientes observaciones realizadas en las entrevistas. En primer lugar, la ley ha constituido un respaldo notable para los sindicatos a la hora de reclamar ante los tribunales determinados derechos asociados a la conciliación y negados por la contraparte empresarial. En segundo lugar, ha sido importante para reclamar la aplicación de derechos adquiridos, como es el caso de los derechos de maternidad: «Sólo basta mencionar que, antes de la ley, muchas mujeres no agotaban la baja por maternidad por las presiones y para hacer mérito en la empresa y poder promocionar» $(\text { E11 })^{9}$. En tercer lugar, la ley y su desarrollo en la negociación colectiva han abierto una oportunidad para modificar el vocabulario y el lenguaje sexista en algunas empresas, cuestión en la que coinciden en señalar algunos representantes sindicales y también empresariales. No obstante, algunos responsables empresariales entrevistados han señalado que no era necesaria esta ley porque tiende a «judicializar» asuntos propios de la gestión de recursos humanos (E13). Es decir, bajo su punto de vista, la ley coarta la capacidad de gestión de la empresa en un tema cuyos contenidos entienden como propios de la gestión de recursos humanos y no como un derecho de carácter general.

En las directivas europeas sobre conciliación, también han desempeñado un papel inductor las directrices relacionadas con el desarrollo del Pilar IV sobre la política de igualdad de oportunidades. Asimismo, la transposición de la direc-

8. E3: Entrevista conjunta a responsable de acción sindical y de seguridad laboral de CCOO.

9. E11: Entrevista a representante sindical en el comité de empresa de una multinacional del sector de la alimentación. 
tiva europea a través de la Ley 31/1995 sobre Prevención de Riesgos Laborales, ha sido otro instrumento jurídico inductor en materia de conciliación.

En este sentido, estudios como el de Bonino y Aragón (2003) confirman la idea del efecto inducido que ejercen las instituciones jurídicas europeas. Siguiendo a Gallardo y otros (2003), las directivas europeas pueden clasificarse en diferentes tipos según su capacidad inductora. Las "directivas fuertes» se refieren a aquéllas que han sido negociadas a nivel supranacional y ejercen una "fuerte» influencia en la legislación de los estados miembros, así como en la negociación colectiva. Por su parte, las «directivas débiles» no tienen especial influencia en la legislación ni en la negociación colectiva. Entre las directivas fuertes se encuentran aquéllas que están relacionadas con la igualdad de oportunidades y la conciliación.

\subsection{La conciliación ocupa un lugar secundario en la negociación colectiva}

Un indicador del escaso grado de extensión y del papel secundario que tienen los temas de conciliación en la negociación colectiva nos lo ofrecen las memorias anuales del CES (2003, 2004). La información que aporta entremezcla cláusulas sobre igualdad de oportunidades con cláusulas referidas estrictamente a conciliación. Los datos referidos a cláusulas de no discriminación o promoción de la igualdad entre sexos aparecía en el 16,1\% de los convenios colectivos y cubría al 39,8\% de las trabajadoras en el año 2002. En el mismo año, los complementos por maternidad aparecen en el 11,9\% de los convenios colectivos. En relación estricta con la conciliación, en la memoria del CES del año 2002 no hay datos. Pero se indica que las cláusulas más extendidas son las licencias, los permisos, las excedencias por maternidad y lactancia, las excedencias para el cuidado de familiares y otras cláusulas relacionadas con la flexibilización del tiempo de trabajo.

Otro estudio reciente (GPI, 2005) y basado en una encuesta a doscientas empresas con un alto grado de feminización pone de relieve que las principales medidas de conciliación (no recogidas por la Ley) son la flexibilidad en la hora de comienzo y fin de jornada (35\%); elección libre de turnos e intercambio $(31,6 \%)$; tiempo parcial con posibilidad de retomar a tiempo completo (26\%); distribución flexible de horas a lo largo del tiempo $(24,6 \%)$; permisos de maternidad más allá de lo que obliga la ley $(8 \%)$; teletrabajo $(5,3 \%)$; ayudas económicas para el cuidado de dependientes $(2,8 \%)$, y guarderías en el centro de trabajo $(1,4 \%)$. Pero, sin duda, ésta es una visión optimista, alejada de los contenidos de la conciliación que se encuentra realmente en los convenios colectivos.

En efecto, los asuntos prioritarios de la negociación colectiva se refieren fundamentalmente al salario y al empleo ${ }^{10}$. Los temas vinculados con la con-

10. Desde los sindicatos, se matiza que la prioridad la constituye más específicamente la «conservación, mantenimiento y ampliación del empleo» (E7). 
ciliación ocupan un lugar secundario y suelen estar enmarcados y subordinados en el capítulo de igualdad de oportunidades. Asimismo, el significado de la conciliación es distinto para los sindicatos y los empresarios. Por un lado, los sindicatos tratan de redefinir a la conciliación como una armonización de la vida laboral, familiar y personal capaz de ser abordada y regulada de forma colectiva, en tanto es una cuestión que afecta al conjunto de la mano de obra, a pesar de la diversidad de situaciones que ésta pueda presentar. Por otro lado, el empresariado tiende a entender la conciliación como una cuestión personal, individual, justamente por las distintas situaciones y cargas familiares de cada cual. Estas dos formas diferentes de entender la cuestión de la conciliación ya constituye de por sí un obstáculo para la negociación colectiva.

No obstante, los obstáculos para otorgar una mayor relevancia a la conciliación en la negociación colectiva se deben tanto a la estrategia empresarial (especialmente en la pequeña empresa) como también a la representación laboral. En cierto modo, ambas son deudoras de una concepción según la cual la temática de la conciliación excede el ámbito laboral y se remite a las peculiaridades de la mano de obra femenina. Algunas de las dificultades señaladas por las personas entrevistadas son las siguientes:

a) La mayoría de los componentes de las mesas de negociación son hombres, la presencia de las mujeres es muy escasa.

b) La cultura sindical en el nivel de empresa está anclada en valores tradicionales patriarcales ${ }^{11}$.

c) La existencia eventual de conflictos con el resto de la plantilla, dada la posibilidad de que la dirección de la empresa redistribuya la carga de trabajo entre quienes permanecen en la misma (situación especialmente patente en el caso de las plantillas feminizadas).

d) Los empresarios son reacios porque la introducción de la conciliación en la negociación puede trastocar la organización del trabajo, así como los horarios y la propia concepción de la jornada laboral.

e) Además, los empresarios consideran que el desarrollo de la conciliación, mediante permisos, puede derivar en aumento de los costes laborales, en particular, también en los casos de fuerte presencia femenina, como es el caso del sector del comercio.

f) Por último, la propia debilitad del estatus contractual del empleo temporal debilita la posición sindical a la hora de negociar ${ }^{12}$.

La vía principal por la cual se introduce la conciliación en la negociación colectiva es a través de la igualdad de oportunidades que está directamente

11. En algunas entrevistas, también se apuntan ciertas diferencias según grupos generacionales de sindicalistas y su nivel cultural, de modo que posiblemente los sindicalistas más jóvenes y con un cierto nivel de estudios valoren de forma más positiva la conciliación (E1, E7).

12. La debilidad sindical derivada de la inestabilidad del empleo ha sido una cuestión especialmente manifestada en el caso del sector del comercio (E8, E9). 
relacionada con el acceso al empleo, la formación y la promoción profesional. La estrategia de los sindicatos consiste fundamentalmente en priorizar la política de igualdad de oportunidades a partir de la cual poder promover distintas medidas de conciliación. En este sentido, el principal reto que plantea esta problemática se refiere a los cambios que implica en la organización del trabajo. En el ordenamiento jurídico, la organización del trabajo es potestad exclusiva de los empresarios: el centro de la cuestión es el poder de decisión. Una oportunidad para influir en la organización del trabajo e introducir el tema de la conciliación aparece cuando se negocia la reorganización y flexibilización de la jornada laboral y del tiempo de trabajo en la empresa. En este sentido, las cláusulas relacionadas con la conciliación más frecuentemente mencionadas son la reducción de jornada, el trabajo a tiempo parcial, la flexibilidad en la entrada y salida del trabajo, el horario laboral comprimido con la finalidad de liberar alguna tarde entre semana y las bolsas de tiempo de trabajo. Sin embargo, las cláusulas más difundidas son las relativas a permisos por maternidad, los permisos complementarios de uno o dos días más de lo estrictamente regulado por ley, los permisos por accidente, fallecimiento o enfermedad de familiares, así como las ayudas económicas de guardería por hijos menores de seis años. Es decir, salvo excepciones ligadas a una cierta negociación de la flexibilidad del horario y de la jornada laboral, en realidad, los contenidos de la conciliación se remiten a un abanico más o menos amplio de permisos. Al respecto, se observa que una verdadera política conciliadora implicaría una organización de la jornada laboral según una lógica menos productivista.

Con todo, los resultados muestran que la negociación colectiva tiene sus límites como impulsora de la conciliación: la difusión de la conciliación depende también de la provisión de servicios. Desde las organizaciones sindicales se entiende que la negociación colectiva no tiene como función proveer de servicios. Ésta sería una tarea de las instituciones públicas que deberían facilitar servicios tales como guarderías o servicios de atención a las personas mayores, etc. que contribuyan a aligerar las cargas domésticas, verdadero centro de la cuestión en términos de una conciliación que, a parte de otros aspectos, supone dar respuesta a una doble carga de trabajo mayoritariamente femenina. Sin embargo, algunos de estos servicios o prestaciones sí que se contemplan en algunas empresas que, por ello, merecen el calificativo de empresas family friendly o empresas que desarrollan buenas prácticas en relación con la conciliación, aunque, como veremos, suele tratarse de casos donde estas políticas son ajenas a la negociación colectiva.

\subsection{La estructura centralizada de la negociación colectiva favorece la irradiación de los objetivos y propicia una mayor cobertura}

Uno de los retos que presenta la gobernanza multinivel es la articulación de la estructura de negociación a efectos de irradiar y coordinar los objetivos de las directivas europeas y de la ley de conciliación, así como desarrollar los acuerdos alcanzados en los convenios colectivos. Un dato interesante y quizás elo- 
cuente de la importancia de la estructura centralizada nos lo ofrece la memoria del CES: "Alrededor del 60 por 100 de los convenios estatales presentan algún tipo de regulación entre la vida laboral y familiar» (2004: 370). Los convenios centralizados, como el de químicas, pastas de papel y cartón, flores y plantas, textil-confección y marroquinería e industrias afines, son los que mejor han incorporado la Ley 3/1999 sobre conciliación de la vida familiar y laboral. Asimismo, son los que han incorporado cláusulas de «interés» (o buenas prácticas) relativas a permisos para preparación para el parto y permisos parentales. Mientras que en los convenios descentralizados, como los territoriales y los de empresas, las mejoras de lo dispuesto por la ley parecen tener una menor importancia y, desde luego, una menor capacidad de cobertura sobre el conjunto de los trabajadores.

Amaia Otaegui (2004: 694-714) argumenta sólidamente que los cuarenta convenios colectivos que se negocian centralizadamente a nivel de estado son, desde el punto de vista cuantitativo y cualitativo, los que incorporan con mayor calidad técnico-jurídica el reconocimiento, la garantía y la protección de los derechos de la Ley de Conciliación. Así, es en éste ámbito estatal donde se registra un mayor número de cláusulas relativas a permisos retribuidos ${ }^{13}$, las mejoras en el periodo de lactancia ${ }^{14}$, el reconocimiento de las parejas de hecho, la concesión de tiempo retribuido para ir al médico e incluso para el acompañamiento de los hijos. Por el contrario, en los convenios de ámbitos inferiores, como los provinciales y los de empresa, es donde se registran las mayores irregularidades, convenios éstos que, en ocasiones, registran cláusulas que están por debajo de la ley, y por tanto son ilegales. Prueba de ello es que en bastantes de estos convenios, de ámbitos inferiores, se siguen recogiendo la antigua redacción del Estatuto de los Trabajadores que limita el permiso del trabajador o de la trabajadora a "enfermedad quirúrgica», término más restrictivo que el de «hospitalización», o no aparecen permisos relacionados con "accidente grave». O incluso cláusulas que, a la luz de la nueva ley de conciliación, son ilegales, como la reducción del acceso en los permisos para los familiares de segundo grado o, más todavía: en algunos convenios se introduce el requisito de ser personal fijo para tener derecho a permiso ${ }^{15}$.

Los convenios de empresa registran una gran diversidad, a diferencia de los convenios estatales que son más homogéneos. En esta línea de mostrar los fuertes contrastes entre ámbitos, podemos observar que, en los convenios de empresa, el permiso de lactancia está escasamente regulado y, además, no se han intro-

13. En los convenios estatales, aparecen registrados como causantes de derecho nuevos conceptos que mejoran el artículo 37.3 del Estatuto de los Trabajadores (ET). Ejemplo de ello es la ampliación de permisos por matrimonio según la antigüedad en la empresa, la ampliación de permisos por nacimiento o fallecimiento o la ampliación o flexibilización de los permisos en caso de enfermedad.

14. El permiso de lactancia (artículo 37.4) aparece recogido en 18 de los 40 convenios estatales. El permiso para exámenes prenatales aparece registrado en 15 de los 40 convenios estatales.

15. Por ejemplo, ello se recoge en los convenios provinciales del Campo de Huelva y de Albacete. 
ducido las novedades que incorpora la Ley de Conciliación. También en los convenios de empresa se registran ilegalidades, tales como la ausencia de los derechos por "hospitalización» o por «accidente grave», de los derechos a «exámenes prenatales», del concepto de "consanguinidad o afinidad», del «segundo grado de parentesco", falta de reconocimiento del permiso al padre por causa de lactancia. Incluso, en los convenios de empresa, se registran ilegalidades más flagrantes aún, tales como restricciones a la utilización del derecho a permiso si el trabajador no tiene una «antigüedad mínima» o no es fijo de plantilla.

Los actores sociales entrevistados reconocen la importancia que tiene una estructura de la negociación colectiva centralizada a la hora de introducir un nuevo tema (y poco usual) en la agenda de negociación. En este sentido, manifiestan algunos entrevistados, los convenios colectivos centralizados o de ámbito estatal, como es el caso del sector químico estudiado, han facilitado una mejor coordinación y difusión del contenido de la Ley de Conciliación que aquellos convenios colectivos descentralizados, como el del comercio. Los convenios colectivos centralizados permiten una difusión de las pautas de conciliación y un desarrollo técnico-jurídico más acorde con el espíritu de la Ley. Los convenios estatales permiten una mejor armonización, articulación y difusión del acuerdo en diferentes ámbitos de un mismo sector de actividad, así como un mejor seguimiento y aplicación del mismo.

Por el contrario, la estructura descentralizada, como es el caso del sector del comercio, presenta serias dificultades para coordinar, difundir y seguir la aplicación de la ley. La descentralización genera diversidad de situaciones y fuertes diferencias territoriales y sectoriales.

\subsection{La conciliación se tiende a gestionar de forma individualizada desde los departamentos de recursos humanos}

A menudo, la cuestión de la conciliación de la vida laboral y familiar se resuelve ordenando una serie de referencias normativo-prescriptivas que tienen como finalidad orientar la política de gestión de recursos humanos. Éste es el caso de cierta literatura como la promovida, entre otros, por Chinchilla y León (2003). Entre las principales medidas, pueden citarse: la flexibilidad horaria, los periodos sabáticos, los descansos o las paradas profesionales para dedicarse a otras actividades, las vacaciones no pagadas, el banco de tiempo libre remunerado, la flexibilidad en los días de permiso y vacaciones cortas, los trabajos compartidos, la semana laboral comprimida, el teletrabajo, las videoconferencias y el contrato de horas anuales en lugar de horas por día. En cuanto a servicios, se recogen en dicha literatura experiencias sobre guarderías en la propia empresa o bien pago de servicios de guardería, plazas reservadas en determinados colegios, "canguros» durante los días de viaje por motivos laborales, información y recursos para el cuidado de personas mayores, asesoramiento fiscal y financiero, asesoramiento sobre la promoción y la carrera profesional, seguro médico, coche de empresa, bono de restaurante, etc. (véase Carrasquer y Martín Artiles, 2005). 
Los resultados de este estudio muestran que esta concepción de la conciliación no es generalizable ni siquiera al conjunto de empleados de una misma empresa. Al contrario, la gestión de esta temática en los términos anteriormente apuntados es restrictiva y limitada a determinados colectivos (directivos, cuadros, técnicos y, en ocasiones, para el personal administrativo). Además, su gestión es individualizada.

Una de las reticencias empresariales para introducir el tema de la conciliación en la negociación colectiva estriba en el cuestionamiento de la organización del trabajo y del poder empresarial, como se puso de relieve anteriormente. Otra de las reticencias proviene de la propia diversidad de situaciones personales de los trabajadores, así como de los propios criterios selectivos inherentes a la gestión de recursos humanos. De hecho, tanto la ley como la gestión cotidiana de la conciliación han venido siendo planteadas bajo la lógica de los permisos, de modo que ello ha redundado a su vez en un planteamiento de gestión empresarial individualizado y jerarquizado según categorías profesionales. En otras palabras, el desarrollo de la conciliación se plantea más bien en clave de gestión de recursos humanos que en términos de relaciones laborales.

En efecto, a tenor de los entrevistados, las prebendas de la conciliación entre la vida laboral, familiar y personal son distribuidas de forma selectiva e individualizada a modo de incentivos personales exclusivo de determinado personal en las empresas privadas: «la conciliación estilo Nuria Chinchilla ${ }^{16}$ sólo está destinada a determinadas categorías profesionales, directivos, técnicos y comerciales, así como a administrativos de los servicios centrales de la empresa» (E14). En la misma línea, otra entrevistada señala: «las empresas socialmente responsables son las grandes multinacionales, pero estas prebendas [de conciliación] se las otorga a directivos y cargos de la empresa. La conciliación sólo afecta a una parte de la plantilla y no se negocia con los sindicatos» (E1). En otras palabras, la gestión de la conciliación es un elemento importante para establecer políticas selectivas, así como para individualizar las relaciones laborales mediante mecanismos de fidelización en las empresas privadas. En la empresa pública, la política sobre conciliación tiene beneficiarios más amplios.

\subsubsection{La conciliación condicionada por la tecnología y la organización del trabajo: una perspectiva empresarial}

Desde el punto de vista empresarial, la cuestión no es sólo individualizar la gestión. El problema estriba también en la organización fabril y en la tecnología de producción en serie. En este sentido, una representante empresarial sostiene que «la conciliación se da allí donde hay personal de administración, directivos, cuadros y oficinas no sometidos a la pauta de la máquina» (E13). La producción estandarizada taylorista dificulta las ausencias de la cadena y la diversificación de horarios, ya que el proceso de trabajo y su ritmo depende

16. Reconocida especialista que ha contribuido a la difusión del tema en el ámbito empresarial. Véanse sus publicaciones referenciadas en la bibliografía final. 
de una lógica maquinal pautada. En la empresa, una multinacional farmacéutica seleccionada como un ejemplo de buenas prácticas, se aduce el mismo problema: las medidas de conciliación se aplican sólo en los servicios centrales de oficina, no en la planta de producción. Desde la perspectiva empresarial, las razones se presentan como obvias: los turnos de mañana-tarde-noche, los ritmos, las cadencias y los horarios de trabajo están condicionados por la maquinaria y su consiguiente organización pautada por la economía de tiempos (E16). La organización del trabajo se muestra como un imponderable que limita el posible alcance de ciertas medidas a favor de la conciliación para la mano de obra directamente productiva.

Además del condicionamiento técnico-organizativo, cabe tener en cuenta que, en muchas empresas, la conciliación forma parte del llamado "paquete social» de la tarea empresarial y es gestionado de forma individual con criterios paternalistas y como premio por el trabajo y la fidelidad. En otros casos, desde la empresa se aduce que la gestión de la conciliación puede resultar dificultosa a tenor de las diversas situaciones personales de los empleados, de ahí que en las entrevistas para reclutar nuevos trabajadores se pregunte y se valore la existencia de redes de parentesco y de apoyo de la familia; un aspecto que se considera especialmente importante en el caso del reclutamiento de mujeres. La gestión de la conciliación da pie a justificar la individualización de trato: incluso en una de las empresas estudiadas se recoge en convenio colectivo el derecho de todos los trabajadores y trabajadoras a disponer de una reunión individual con la dirección de recursos humanos (E13 y E14).

\subsection{Las buenas prácticas de conciliación constituyen ejemplos de interés o prácticas positivas en términos relativos}

En la mayoría de los convenios colectivos, se repiten las cláusulas que ya prevé la ley, tales como licencias por maternidad, protección por embarazo, suspensión del contrato con reserva del puesto de trabajo, ausencias laborales por lactancia, reducción de jornada por cuidado de hijos o personas dependientes y excedencias por cuidado de hijos (CCOO; UGT; CEOE-CEPYME, 2003). No obstante, la ley se incorpora frecuentemente de forma incompleta en la negociación colectiva, hasta el punto que se pueden registrar situaciones paradójicas, como ponen de relieve Bonino y Aragón (2003: 117), llegándose incluso a empeorar en los convenios colectivos lo dispuesto por la ley, como, por ejemplo, la omisión de «causa de derecho de permisos para los familiares hasta segundo grado de consanguinidad o afinidad». Por tanto, sólo el mero hecho de reflejar la propia ley puede considerarse como un "hecho positivo».

En relación con la transposición de la ley 39/1999 al contenido de los convenios, algunos analistas destacan como buenas prácticas, o «ejemplos de interés» que constituyen mejoras frente a otros, los convenios estatales del sector químico, perfumería e industrias afines, el de telemarketing y el estatal de seguros. En lo que respecta a los permisos retribuidos, éstos han constituido un tema tradicional en los convenios; no obstante, su vinculación con cuestiones de igual- 
dad de género y de conciliación es reciente. Las mejoras respecto a lo dispuesto por la ley, quizás se encuentran con mayor frecuencia en los convenios sectoriales estatales, éste es el caso, por ejemplo, de los «permisos retribuidos para acompañar a hijos y a familiares al médico» (Bonino y Aragón, 2003: 118). No obstante, también en otros convenios de ámbito territorial y de empresa se recogen cláusulas parecidas, pero con notable menor capacidad de cobertura sobre el conjunto de los trabajadores y las trabajadoras.

Las buenas prácticas se han tendido a idealizar de forma interesada y propagandística como modelos de referencia en la lista "Best place to work» y con la finalidad de legitimar la imagen pública de la empresa. La difusión de la obra de N. Chinchilla en los medios empresariales e institucionales ha constituido un ejemplo de ello, pero bastante alejado de la realidad. Las buenas prácticas son sólo casos muy limitados, poco generalizables y, sobre todo, basados en prácticas de prebendas selectivas destinadas a la fidelización de personal directivo o técnico y a los cuadros responsables de las empresas. En muchos casos, la difusión pública y los premios concedidos a las empresas que impulsan esas buenas prácticas han tendido a distorsionar la realidad de la cuestión.

Otro problema importante es la propia definición de buenas prácticas. La mayoría de las personas entrevistadas coinciden en la idea de que las buenas prácticas consisten en mejorar las disposiciones de la ley, en tener referencias «positivas» o ejemplos de «interés». Es decir, las buenas prácticas tienen un sentido menos grandilocuente y más modesto de lo que da a entender cierto tipo de usos empresariales, como el que presentamos en el epígrafe siguiente.

\section{5.1. Programa Trébol: ¿un modelo de conciliación?}

Uno de los casos estudiados es el de una multinacional del sector farmacéutico que tiene un planteamiento filosófico simbolizado en la imagen de un trébol: la primera hoja es la parte social y laboral, la segunda hoja es la parte personal y la tercera hoja es la parte familiar. El reto es armonizar los tiempos de estas tres hojas del trébol para conseguir cuatro objetivos: 1) aumentar la eficiencia y eliminar la burocracia; 2) conseguir una mentalidad positiva y equilibrada de los miembros de la comunidad empresa; 3) llegar a una mejora del entorno social y laboral de la comunidad empresa, y 4) proveer al «colaborador» de una serie de recursos y servicios de ayuda.

La gestión de la conciliación es, en este caso, individualizada, al tiempo que no contempla la representación sindical de los trabajadores y las trabajadoras. Indicativo de esta actitud antisindical es que la puesta en marcha de dicho programa se ha promovido como una iniciativa de la dirección de recursos humanos, y no como resultado de un posible acuerdo o abierto a ello. De hecho, el programa Trébol nació ante el exceso de trabajo y el malestar entre los empleados surgidos después de la fusión con otra empresa. Hoy, el programa Trébol tiene una importante función en la imagen pública de la empresa, así como en la construcción de la legitimidad interna entre los empleados de las oficinas centrales. El programa proporciona la apariencia de un "clima propicio» (E16). Sin embargo, la presión de la economía de tiempos persiste, sólo que 
ahora interiorizada en forma de autogestión del propio tiempo de trabajo. Otra forma de presión es a través de la dirección por objetivos. Una parte del salario depende de los objetivos alcanzados anualmente, la otra parte es un salario fijo a tenor de que los empleados realicen distintas actividades no relacionadas directamente con los objetivos. El sistema de incentivos por objetivos obliga a la autodisciplina, a interiorizar y a autogestionar la administración del tiempo.

El lema de la empresa, «facilitar los recursos que apoyen el balance entre la vida laboral, familiar y personal», simplificado en la idea del trébol, constituye una verdadera ideología para la integración de sus empleados bajo criterios neopaternalistas. Dicha ideología parece enmascarar y encubrir la dedicación de mucho tiempo a las actividades directas e indirectas de la empresa. El idílico trébol es una planta voraz: absorbe sutilmente el tiempo y la mente de sus empleados. La sutilidad estriba en la interiorización de la disciplina temporal: de hecho, los empleados no parecen ser muy críticos con el programa Trébol, pero perciben que cumplen muchas horas de trabajo (E17). Por consiguiente, de la lectura entre líneas de esta «filosofía del trébol» y de sus objetivos, podemos colegir una interpretación neofuncionalista de la gestión empresarial expresada mediante un discurso de integración armoniosa y sin conflicto de los trabajadores, que participan y a la vez generan los valores de la cultura de la empresa como una comunidad de intereses e identidades compartidas. El espíritu microcorporativista se identifica con un aire jovial y deportivo que rinde culto al propio cuerpo y, por extensión, al cuerpo de la empresa.

\section{Conclusiones}

Efectivamente, en primer lugar, las directivas europeas parecen haber desempeñado un importante papel inductor para promocionar gradualmente el tema de la conciliación a través de la negociación colectiva. El complejo ejercicio de gobernanza ha ejercido una notable influencia en la incorporación de la conciliación en la agenda de los actores sociales, tema que, de otro modo, no estaría hoy presente, por no ser éste un tema prioritario desde el punto de vista de la acción. Quizás se pueda aducir que el contenido de los mismos es en términos genéricos y vaporosos, pero lo cierto es que está en la agenda de negociación, que no es poco. La influencia de la gobernanza no es determinante y sí muy genérica y limitada en el ámbito sectorial, territorial, local y de empresa. Uno de los problemas con que tropieza la gobernanza es la propia estructura de transmisión de la política de negociación, como hemos contrastado en la primera hipótesis específica.

En segundo lugar, cabe señalar que, a pesar de la inclusión de la conciliación en la agenda de negociación, este tema ocupa un lugar secundario en la negociación colectiva, cuestión demostrada ya también por varias investigaciones y que nosotros constatamos igualmente en la segunda hipótesis. No obstante, la Ley de Conciliación se va extendiendo gradualmente en los con- 
venios colectivos, aunque con desigual suerte: con una mejor aplicación en los convenios estatales y con mayor diversidad en los convenios de ámbito provincial, comarcal y de empresa.

Si bien la Ley de Conciliación de la Vida Familiar y Laboral (Ley 39/1999) introduce diversos cambios con respecto a la legislación vigente anterior, éstos no suponen avances significativos, dado que se limitan, en gran medida, a legislar una serie de permisos laborales que resultan insuficientes en numerosos terrenos, al tiempo que no recoge la totalidad de las medidas contenidas en las dos directivas europeas. Muestra de ello es que muchas de las demandas sindicales y de las organizaciones feministas no fueron incluidas en el texto finalmente adoptado. A modo de ejemplo, la Ley hace posible que los hombres ${ }^{17}$ asuman responsabilidades familiares, pero no impulsa ni incentiva activamente este hecho ${ }^{18}$. Una de sus limitaciones más claras es que su aparente neutralidad esconde en realidad una fuente de desigualdades de género importante, como se pone de manifiesto en la ausencia de medidas de discriminación positiva en materia de permisos o excedencias que incentive a los hombres a asumir responsabilidades.

En tercer lugar, y en estrecha relación con el aspecto anterior, se observan diferencias en la irradiación y aplicación de la Ley de Conciliación y de sus objetivos según sea la estructura de la negociación colectiva centralizada o descentralizada. La estructura centralizada de los convenios estatales no sólo facilita una mayor irradiación, sino también una mejor gobernabilidad en la administración de los objetivos de conciliación, como hemos observado en el sector químico. El desarrollo técnico-jurídico y el reconocimiento, la garantía y la protección de los derechos de conciliación están mejor definidos en los convenios estatales que en los provinciales, territoriales y de empresa. La estructura descentralizada de la negociación colectiva, como es el caso de los convenios provinciales, comarcales y de empresa, presenta una gran diversidad y heterogeneidad en las cláusulas relacionadas con la conciliación. Incluso, en los del ámbito de empresa se registran cláusulas que empeoran y restringen la aplicación de la ley, y por tanto son flagrantemente ilegales.

En cuarto lugar, hemos podido constatar que la política de conciliación tiene distintos significados para los actores, razón por la cual también las estra-

17. Tal y como muestra una encuesta reciente sobre conciliación (GPI, 2005), tan sólo un 2,5\% de los hombres ha hecho uso de las bajas por maternidad-paternidad; mientras que en el mismo estudio la respuesta de las empresas es más baja aún: un 1,5\%.

18. Uno de los aspectos que subyace al respecto es la controvertida cuestión salarial: el menor salario femenino desincentivaría que los padres solicitasen el permiso de maternidad-paternidad, excedencia o reducción de jornada, más aún en los casos de permisos no retribuidos o que impliquen una reducción salarial. En este sentido, cabe mencionar la Ley catalana 6/2002 de «Mesures relatives a la conciliació del treball amb la vida familiar del personal de les administracions públiques catalanes i de modificació dels artícles 96 i 97 del Decret legislatiu 1/1997» que introduce el derecho del funcionariado y del resto de personal afectado a percibir el 100\% de la retribución en el supuesto de reducir un tercio de la jornada de trabajo para el cuidado de un menor hasta que tenga un año. 
tegias de los mismos son visiblemente distintas cuando nos situamos a nivel de empresa. Para los sindicatos, la conciliación es un tema a gestionar a través de la acción y negociación colectiva, mientras que para los empresarios la conciliación es un tema a gestionar individualmente desde recursos humanos. En añadidura, hemos podido comprobar la idealización de la conciliación y de lo llevado a cabo en ciertas buenas prácticas, así como de modelos de conciliación que son tomados como referencia generalizada para todos los trabajadores y trabajadoras, cuando en realidad estas condiciones de conciliación son limitadas a determinados segmentos de empleo, como el personal administrativo, técnico y/o directivo de distinto nivel, y a modo de política de fidelización.

Finalmente, hemos puesto de relieve que el concepto de buenas prácticas tiene un doble significado. Por un lado, hay quienes lo entienden como simples mejoras en determinadas cláusulas, que se convierten en «referencias de interés» o en "acciones positivas» $y$, por tanto, podría marcar una cierta orientación de aspectos a conseguir y mejorar en los convenios colectivos, y un segundo significado de tipo propagandístico destinado a mejorar la imagen y la legitimidad pública de la empresa. En este sentido, las «buenas prácticas» se convierten en algo etéreo y vaporoso, que en ocasiones esconden políticas de recursos humanos que podríamos calificar de neofuncionalistas, neopaternalistas y antisindicales. Las «buenas prácticas», como referencia para mejorar el proceso de retroalimentación de la política europea a través de sus mecanismos de gobernanza, es más un desideratum que una realidad empírica.

\section{Entrevistas referenciadas}

\section{Sindicatos}

E1. Responsable Secretaría de la Mujer de CCOO.

E2. Secretaría de la Mujer Comercio.

E3. Responsable de Acción Sindical de CCOO y responsable de Seguridad Laboral de CCOO.

E4. Responsable de la Mujer Ámbito Industria. Sector Químico CCOO.

E5. Responsable de la Mujer Fiteqa CCOO.

E6. Responsable de la Negociación Colectiva de UGT.

E7. Responsable de la Secretaría para la Igualdad de Oportunidades de UGT.

E8. Responsable de la Federación de Comercio de UGT.

E9. Responsable de la Federación de Química de UGT.

E10. Responsable de la UGT Federación de Comercio, Sector Juego.

\section{Asociaciones empresariales}

E11. Responsable Fomento Nacional de Cataluña. Federación Comercio.

E12. Responsable Fomento Nacional de Cataluña. Federación FEDEQUIM.

\section{Empresas}

E13. Dirección de Recursos Humanos de una multinacional de comercio-alimentación. 
E14. Presidenta del Comité de Empresa de una multinacional de comercio-alimentación.

E15. Dirección de Recursos Humanos de una multinacional de químicas.

E16. Dirección de Recursos Humanos de una multinacional químico-farmacéutica.

E17. Responsable del Comité de Empresa de una multinacional químico-famacéutica.

\section{Bibliografía}

Albert, M. (1992). Capitalismo contra capitalismo. Barcelona: Paidós.

- (1996). «The single currency vs. and the Rhine Model». Transfer Review, núm. 2.

ARGÜELLES, A.R. y otros (2004). Igualdad de oportunidades y responsabilidades familiares. Madrid: Consejo Económico y Social.

Bonino, C.; ARAGÓN, J. (2003). La negociación colectiva como instrumento para la igualdad laboral entre mujeres y hombres. Madrid: Ministerio de Trabajo y Asuntos Sociales.

BordognA, L.; CelLA, G. P. (1999). «Admission, exclusion and correction: the changing role of the state in industrial relations». Transfer Review, vol. 5; núm. 12.

CALMFORS, L.; DrIFFILl, J. (1988). «Bargaining structure, corporatism and macroeconomic policy». Economic Policy, vol. 6: 13-47.

CARRASQUer, P.; MARTín ARTILES, A. (2005). «La política de conciliación de la vida laboral y familiar en la negociación colectiva». Revista Cuadernos de Relaciones Laborales, vol. 22, número 3: 131-150.

CES (2001). «Libro Blanco de la Comisión sobre la Gobernanza en Europa». Boletín Observatorio de Relaciones Industriales, núm. 44.

- (2003a). La negociación colectiva como mecanismo de promoción de la igualdad entre hombres y mujeres. Madrid: Consejo Económico y Social. Colección Informes.

- (2003b). Memoria sobre la situación socioeconómica y laboral en España. Madrid: Consejo Económico y Social.

- (2004a). Memoria sobre la situación socioeconómica y laboral de España. Madrid: Consejo Económico y Social.

- (2004b). Panorama sociolaboral de la mujer en España. Boletín núm. 38.

CCOO (2003). Negociación colectiva y género: Una apuesta de futuro. Madrid: Secretaría Confederal de la Mujer de CCOO.

CCOO; UGT; CEOE-CEPYME (2003). Consideraciones generales y buenas prácticas sobre igualdad de oportunidades entre hombres y mujeres en la negociación colectiva. Comisión de Seguimiento del Acuerdo de NC, 2003.

ChINCHILla, NuRIA; LEÓN, CONSUElo (2003). Les millors pràctiques de conciliació treball-familia a l'empresa. Barcelona: Generalitat de Catalunya.

COMMISSION EUROPÉENNE (2003). Conciliation de la vie professionnelle et familiale en Europe. Bruselas: Divission Emploi et Affaires Sociales.

ETUI (2003). Our proirities. Bruselas: European Trade Union Institute

GALLARDO, R. y otros (2003). Los acuerdos fuertes y débiles frutos del Diálogo Social Europeo. Barcelona: Fundación para el Diálogo Social, Working Paper.

GPI (2005). Estudio sobre la conciliación de la vida familiar y laboral: situación actual, necesidades y demandas. Madrid: Instituto de la Mujer.

KÖHLER, H.D.; MARTín ARTILES, A. (2005). Manual para la sociología del trabajo y las relaciones laborales. Madrid: Delta Publicaciones.

LÓPEZ, M.T.; VAliÑo, A. (2004). Conciliación familiar y laboral en la Unión Europea. Madrid: Consejo Económico y Social. 
MACINNES, J. (2004). «Work-life balance: three terms in seach of definition». Ponencia presentada en el seminario L'organització social del temps: conciliació de la vida laboral i familiar. QUIT-Universidad Autónoma de Barcelona.

MaYnTZ, R. (1998). New Challange to governance. Theory. Florencia: European University Insitute.

- (2002). The state and civil society in modern governance. http://www.clad.org.ve/ana les6maintz.htlm

OTAEGUi, A. (2004). «El tiempo de trabajo y la conciliación de la vida laboral y familiar». En: ESCUDERO, R. La negociación colectiva en España: una visión cualitativa. Madrid: CCOO.

Quintanilla, B. (2005). «La conciliación de la vida laboral y familiar en el marco jurídico actual». Cuadernos de Relaciones Laborales, vol. 23, núm.1: 95-129.

SCHARPF (2000). Gobernar en Europa. Madrid: Alianza Editorial.

SCHMiTTER, P. (1988). «La mediación de intereses y la gobernabilidad de los regímenes en Europa Occidental». En: BERGER, S. La organización de los grupos de interés. Madrid: Ministerio de Trabajo y Asuntos Sociales.

TORNS, T. (2005). «De la imposible conciliación a los permanentes malos arreglos». Cuadernos de Relaciones Laborales, vol. 23, núm.1: 15-33.

TraXler, F. (2002). European Monetary Union and collective bargaining. Barcelona: Institut de Ciències Politiques i Socials. Working Paper.

Traxler, F.; Blaske, S.; KitTel, B. (2002). National Labour Relations in Internationalzed markets. A comparative study of institutiotions, change and performance. Oxford: Oxford University Press. 